\title{
Research on the Influence of Contemporary Youth's Social Anxiety on Worshipful Consumption Behavior
}

\author{
Chaojia Zhou \\ College of Business \\ Shanghai University of Finance and Economics \\ Shanghai, China
}

\begin{abstract}
In the era of market economy, consumers' psychological needs are the root cause of consumer behavior. Only by firmly grasping the characteristics of consumers can companies seize market opportunities. It is precisely because of the continuous advancement of social reform and transformation that the economic individuals and organizations on the market are facing unavoidable pressures. A series of social issues such as further studies, employment and marriage affect the construct and harmony of various groups of people's lives. As the most dynamic component of the market, the new generation of adolescents is able to reflect the characteristics of the era towards some extent in their market performance. It is of practical significance to study the influence of contemporary adolescents' psychology on their consumer behaviors. One obvious feature of contemporary youth groups is that they belong to a large segment of the single-generation market. Their growth environment, level of education, inner appeal, and value pursuit are all different from those of their fathers. This article starts from a common social anxiety in young people and uses idol worship as a mediator, then puts forward three assumptions. First, social anxiety has a significant positive effect on worshipful consumption behavior; second, Idol worship has a significant positive effect on worshipful consumption behavior. Third, Idol worship plays an intermediary role between social anxiety and worshipful consumption behavior. The purpose is to explore whether anxiety has a direct or indirect impact on their worship behavior. This study prepared questionnaires and conducted correlation and regression tests on this model. The final empirical results obtained were that the model hypotheses passed the test and the theoretical hypothesis was established.
\end{abstract}

Keywords-social anxiety; idol worship; worship consumption

\section{INTRODUCTION}

\section{A. Research Background and Significance}

1) Social anxiety in the era of market economy: With the continuous advancement of the market economy, the dramatic adjustments of the social structure and the drastic changes in the environment have accelerated the competition and transformation of society. At the same time, the physical and psychological fitness degree of the members of the society to the new environment is difficult to achieve a complete combination, and the irrational behaviors such as depression, restlessness, and temperament exhibited by the individual are also called anxiety. The group status derived from the aggregation and generalization of individual anxiety leads to the generation of social anxiety. Investigating its meaning, anxiety is an emotional reaction mode that individuals exhibit in the face of uncertainty, threat, and uncontrollability. Only when individual effects gather to a certain extent form social tension can form social anxiety [1]. Social anxiety has become the norm in today's society, and it is a social psychological problem that everyone cannot avoid. As for the main research object of this paper - adolescents, social anxiety can be expressed as survival anxiety, developmental anxiety, and moral anxiety. China has implemented the onechild policy for 37 years, and is now active in the 15-30 age group. The changes of the background of the times and the closure of the growing environment have determined that the only child has more interpersonal relationships than the non-only child. The barriers to communication, self-identity, and the loss of trust in society are more likely to cause anxiety and irrational behavioral tendencies when faced with academic, employment, and emotional problems.

2) Youth idol worship and worship consumption: Under the impact of popular culture and new Internet media, the trend of idol worship came into being. Idol worship can be said as a concrete expression of the emerging cultural form, and can also be said as the spiritual sustenance of individual emotions. In the study of Feng Xiaotian, most of the only children have strong affinity needs, long-lasting needs and support needs [2], that is to say, in young people such as lack of parental companionship and long-term high-pressure competition. It is easy to generate anxiety about self and social identity. When it is unable to obtain external emotional counseling, it is easier to generate ideological dependence on idols to obtain a sense of distant relatives. The most objective external effect brought about by idol worship is the worship consumption. Worship consumption is essentially a kind of compensatory consumption, which refers to the consumption form produced by making up for a certain psychological deficiency or satisfying certain 
psychological needs [3]. The object of worship consumption includes not only tangible products such as idols' peripheral products, concert tickets, but also intangible products such as idols' performances and services. Young people try to establish a special connection with idols through worship consumption, so as to obtain inner spiritual disposition and satisfaction. According to the data, the main force of the idol economy is concentrated in the $18-28$ age group, with a total consumption ratio of $70.2 \%$.

3) Research significance: The purpose of this paper is to explore how and to what extent the anxiety of contemporary adolescents affects their adventurous consumption, and explore whether social anxiety can induce idolatry and lead to blindly admired consumer behavior, resulting in the idol economy.

From the theoretical point of view, this paper enriches the consumer behavior from the perspective of empirical evidence, and expands the empirical research gap of the new generation of adolescents in the state of social anxiety about worship consumption.

From the practical point of view, the prosperity of today's "fans era", new media and enterprises linked to idols must first thoroughly explore the consumer psychology characteristics and needs of "fans" in order to occupy the market. This paper analyzes the psychological normality of adolescents from the realistic level of social anxiety, tries to establish a certain internal relationship with the worship consumption of adolescents, and helps the society to understand its root causes more comprehensively, and also helps enterprises to find out potential consumer demand to seize opportunities.

\section{B. Research Thoughts}

The full text will be organized as follows:

The first part is the introduction. The introduction is an introduction to the background and significance of this paper. It clarifies the textual thinking of this paper and proposes the innovation of this research.

The second part is the literature review. It is a combing and summarizing of related literatures studied by predecessors, and defines the concepts of social anxiety, idolatry complex and worship consumption.

The third part is the research design. It is based on the correlation between social anxiety, idol worship, and worship consumption, puts forward reasonable assumptions, and selects the scale measurement tools with good reliability and validity and appropriate samples for investigation.

The fourth part is the empirical analysis and hypothesis testing. This part of the content is mainly to analyze and explain the data to verify the rationality of the hypothesis.

The fifth part is the conclusion and outlook. The last part of this paper is to discuss and summarize the results of this study, and make recommendations and prospects based on the inadequacies.

\section{Innovation}

The innovation of this paper is to analyze the potential consumption psychology of adolescents from the perspective of social groups, using social anxiety as an independent variable, and idol worship as a mediator to establish and validate the model of adventurous consumption behavior. This paper adds another original analysis perspective to the study of consumer behavior, and fills the vacancies in current research in China and foreign countries.

\section{LITERATURE REVIEW}

Freud, the founder of the famous psychoanalytic school, divided anxiety into three categories from the perspective of psychology: objective anxiety, mental anxiety, and moral anxiety, and he proposed six solutions to anxiety, namely repression, dislocation, projection, reaction, fixation, and regression [4]. According to the research of Chinese scholars Wu Zhongmin and Qiu Min, as far as China's current situation is concerned, social anxiety presents a clear and differentiated orientation, and the solution of anxiety is easy to seek external positive asylum [5]. At present, anxiety is no longer limited to survivability anxiety, but more is reflected in the level of developmental anxiety. The liberalization and openness of the market, coupled with the normative implementation of social welfare policies, have prompted economic entities to gradually get rid of poverty and become rich. People began to focus more on the comprehensive development of the spiritual field. The scarcity of resources has brought about the intensification of market competition and the sharp increase in social risks. Young people face multiple pressures from academics, employment, interpersonal and family in the process of personality traits, enticing them to intensify the exclusion of uncertainty and non-standard social norms when they are integrated into a diversified environment, and it will be easy for them to lose understanding and recognition of society, and then fall into a state of anxiety and self-contradictory anxiety. As a new generation of young people who cannot be ignored as a phenomenon of social anxiety, the impact of group social anxiety, such as questioning self-identity and social authority, reducing satisfaction with life, loss of social belief, and the occurrence of uncontrolled behavior, not only has a serious impact on the growth of adolescents, but also has a strong negative effect on the whole society.

Idol worship is essentially a kind of sub-culture that gives special symbolic meaning to the spiritual sustenance object, highly romantic and absolutely idealized. It is a subculture that is universally formed and exists in the contemporary youth group for a long time. According to the relevant literature of Yue Xiaodong [6], the way of idolatry can be divided into idol psychological identity, idol emotional attachment, idol commodity consumption. The characteristics include intergenerational differences, gender differences, and age differences. In combination with Freud's theory, idol worship is a concrete manifestation of displacement, replacing one of the available figurative with another, non-obtainable object, at which point the object of anxiety is transferred or, more accurately, is suppressed and replaced by a relatively stable mood or expectation. In 
layman's terms, adolescents in the puberty in order to get rid of their attachment to their parents, their rebellious psychology becomes more intense. For the confusion and anxiety of reality, when pursuing the identity of the self, they are more willing to take advantage of the risk-avoiding way to use the transfer of emotions, taking the idol as a commodity to imitate and consume, and to obtain sensory happiness through the achievement of idols, so that they can maintain expectations for their future. According to the theory of scholar Chen Gang, "consumption is the ultimate goal of making idols, and imitating idol itself is also a consumption behavior" [7]. The spread of mass media and the proliferation of the information economy, transparency, platform and interaction have shortened the distance between fans and idols. "Emotional sustenance" has become more and more concrete and substantive, and it also promotes the idol economy to become the economic support of the entertainment industry.

\section{RESEARCH DESIGN}

\section{A. Research Hypothesis}

Demographic variables such as gender, age, and whether they are only children are taken as control variables, social anxiety as independent variable, idolatry as mediator, and eventually worship consumption as a dependent variable, forming a model hypothesis of worship consumption. For the logical relationship described by the model, the following theoretical assumptions are made (a list of assumptions is as follows in "Table I"):

TABLE I. SUMMARY LIST OF THEORETICAL HYPOTHESES

\begin{tabular}{|l|l|}
\hline Hypothesis & \multicolumn{1}{|c|}{ Content } \\
\hline P1 & $\begin{array}{l}\text { For adolescents, social anxiety has a } \\
\text { significant positive impact on idol } \\
\text { worship. }\end{array}$ \\
\hline P2 & $\begin{array}{l}\text { For adolescents, idol worship has a } \\
\text { significant positive impact on worship } \\
\text { consumption. }\end{array}$ \\
\hline P3 & $\begin{array}{l}\text { For adolescents, idol worship plays a } \\
\text { mediating role in social anxiety and } \\
\text { worship consumption. }\end{array}$ \\
\hline
\end{tabular}

P1: For adolescents, social anxiety has a significant positive impact on idol worship.

The new generation of adolescents will undergo a process of pursuing self-identity before they fully shape their self-worth. In this process, adolescents gradually began to get rid of the complete dependence on the original family, but apparently because of the immature and unstable nature of the adolescents, it also determines that during the whole differentiation stage, individuals will have cognitive biases towards self, uncertainty, and good and evil. The gap between reality and ideal will produce and expand the degree of individual anxiety, and the scale of individual anxiety is also the premise of the formation of social anxiety. However, the birth of idols will create Utopia for the "idealism" of the young people and give them a realistic definition. In order to alleviate the inner anxiety and anxiety, young people will smell a smooth message from the mainstream media, online social software and other platforms to gain a sense of belonging through emotional transfer.

P2: For adolescents, idol worship has a significant positive impact on worship consumption.

Idol worship is a necessary and inadequate condition for worship consumption, and the two are closely related. As a kind of idol worship, worship consumption is the most iconic and material expression of idol worship, and it is also its ultimate goal. Therefore, it is assumed that the degree of idol obsession is positively related to the level of worship consumption.

P3: For adolescents, idol worship plays a mediating role in social anxiety and worship consumption.

As a form of emotional transposition, idol worship plays a mediating role in the generalization of social anxiety and worship consumption. According to consumer behavior research, potential consumer psychology induces the generation of consumer behavior. With the help of the new forms of mass media and the Internet, adolescents seek to have a sense of identity and resonance in the process of dealing with others, and use idol worship as a medium to seek contact with the outside world. It is a relatively low-cost and cost-effective way of "consumption". It not only makes young people build a special connection between other peers or non-peer ages [8], but also makes adolescents find spiritual comfort in their self-lost anxiety. So here, it is supposed that idol worship can have a mediating effect in social anxiety and worship consumption.

\section{B. Research Tools}

In order to control the reliability and validity of the research, this paper adopts the mature scales in China and foreign countries, and on this basis, appropriate modifications are made to meet the research needs, and all three scales are measured by the Likert 5 scale. In addition, other variables that may affect the above variables are controlled, including the respondent's age, gender, education, demographic variables such as only children, and other variables such as monthly disposable income.

- State-trait Anxiety Scale (STAI) was established by Charles. D. Spielberger et al., consisting of the subscales that evaluate two different types of anxiety, this paper extracts the partial scale of T-AI for the study of stable anxiety and tension personality traits.

- The Celebrity Attitudue Scale (CAS) is based on the CAS scale developed by Mc Cutcheon et al. on the basis of previous work to measure the health of adolescent idolatry. The scale will distinguish the degree of idol worship from low to high: entertainment social type, strong feeling type, and pathological borderline type. The purpose of entertainment social type worship is only for entertainment and common language with peers; strong feeling type is the formation of strong, compulsive attachment to idol; pathological borderline type is a deeper worship than the former 
two, and it is an over-identification and forced worship of stars.

- According to Pan Chaoyun's research, the scale of worship consumption uses seven items.

\section{EMPIRICAL ANALYSIS AND HYPOTHESIS TESTING}

\section{A. Sample Data Description}

The logical chain studied in this paper is the correlation between adolescents' social anxiety and their admiration consumption. Therefore, the main targets are contemporary adolescents. The survey area is distributed throughout the country, mainly in the Shanghai area. In the survey form, which combined online and offline questionnaires, 200 questionnaires were distributed and 187 were collected, of which 170 were valid questionnaires, and the effective rate was $85 \%$. According to the classification of human demographic variables, the relevant proportions are organized as follows. According to the data, the majority of the respondents were female, with a total proportion of $64.1 \%$; the age distribution was concentrated on 18-25 years old, accounting for $74.1 \%$ of the total, which was consistent with the definition of the adolescents in this study; According to the aspect of the only child, $65.3 \%$ of the respondents were the only-child of their families.

\section{B. Correlation Analysis}

Correlation analysis refers to the analysis of two or more variables, focusing on their closeness. In order to more accurately describe the degree of linear correlation between variables, the correlation can be analyzed by calculating the sample correlation coefficient $r$. The value of $r$ is between -1 and 1 . The closer the $|r|$ is to 1 , the closer the correlation between the variables is, and the less close on the contrary. When $0<\mathrm{r}<1$, the variables are positively correlated. When $1<\mathrm{r}<0$, there is a negative correlation between variables. This paper makes a bivariate correlation analysis among the four control variables (gender, age, whether he or she is the only child, monthly disposable income) and the three main variables (social anxiety level, idol worship degree, worship consumption level), and a pairwise correlation analysis among the three main variables to explore the relationship density between the variable elements.

\section{1) Correlation analysis between control variables and} main variables:

Through the data test, the following results were analyzed:

When gender exists as a control variable, gender has a significant positive correlation with the idol worship dimension. At this time, the correlation coefficient $r$ is 0.177 , and the Sig.p value is 0.029 , indicating that the significance is significant when the two-sided significance test is 0.05 . At the same time, the correlation between gender and social anxiety and the degree of worship consumption is not significant.
From the age dimension, the correlation between age and independent variables, mediator variables, and dependent variables was not significant.

From the perspective of whether the person is an only child, the remaining idol worship dimensions show a significant negative correlation. At this time, the correlation coefficient $r$ is -0.209 , and the Sig.p value is 0.01 , indicating that the significance is remarkable when the two-sided significance test is 0.01 .

Finally, from the perspective of disposable income, it is significantly positively correlated with social anxiety and negatively correlated with idol worship.

2) Correlation analysis results between the main variables:

After analyzing the relationship between the control variables and the main variables, it is also necessary to do a correlation analysis between the independent variables, the intermediate variables, and the dependent variables. From the data, social anxiety and idol worship showed a significant positive relationship, $\mathrm{r}$ value between $0.3-0.5$, Sig.p value of 0.029 , indicating that the significance is significant when the two-sided significance test is 0.05 . The correlation coefficient between idol worship and worship consumption is higher, the $r$ value reaches 0.666 , and the Sig.p value is 0.00 , indicating a strong positive correlation when the twosided significance test is 0.01 . That is, the three variables studied in this paper are significant in pairs and related.

\section{Regression Analysis and Mediation Effect Test}

After the correlation analysis of the seven variables, regression analysis is needed to further discover the degree of interaction between the variables. Regression analysis is a quantitative statistical analysis method used to determine the interdependent relationship between two or more variables. According to the relationship between independent variables and dependent variables, it can be divided into linear regression analysis and nonlinear regression analysis. This paper mainly uses linear regression analysis.

According to the test method of mediating effect introduced by Wen Zhonglin (2004) [9] in his article, the following flow chart can be drawn ("Fig. 1"). Where $X$ is the independent variable, $\mathrm{Y}$ is the dependent variable, and $\mathrm{Z}$ is the possible mediating variable. $\mathrm{a}, \mathrm{b}$, and $\mathrm{c}$ all represent direct effects, while the effect from $\mathrm{X}$ to $\mathrm{Z}$ is the indirect effect. The coefficient $c^{\prime}$ represents the direct effect of $X$ on $\mathrm{Y}$ after controlling $\mathrm{Z}$, and $\mathrm{b}$ is the effect of $\mathrm{Z}$ on $\mathrm{Y}$. If $\mathrm{c}^{\prime}$ is not significant and $b$ is significant, the effect of the independent variable works entirely through the intermediary agent. This is called "complete mediation effect". If both b and c' are significant, but c' value decreases compared with $\mathrm{c}$, it means that the independent variable has a direct effect on the dependent variable, and also has an indirect effect on the dependent variable through the intermediate variable. This situation is called "partial mediation effect." In the following, human demographic variables will still be used as control variables, social anxiety as an independent variable, idol worship as a mediator, and worship consumption as a 
dependent variable to establish a regression model for linear regression analysis.

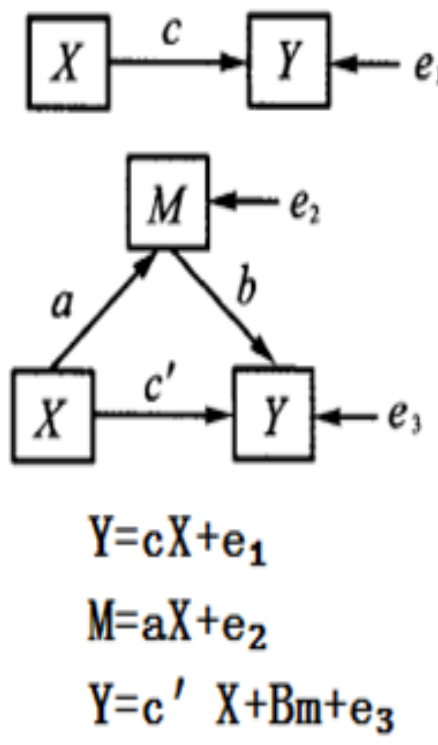

Fig. 1. Intermediary effect test equation and flow chart.

1) Regression analysis of social anxiety and idol worship: According to the process of mediating effect test, the independent test and the dependent variable should first be tested by regression, that is, the coefficient $\mathrm{c}$ is tested. Under the condition of adding control variables, the correlation coefficient $r$ between the social anxiety of the independent variable and the worship consumption of the dependent variable is 0.278 , and the Sig.p value is $0.024<0.05$, indicating that it is significant at the level of 0.05 , which means that there is a significant positive correlation between the independent variable and the dependent variable.

2) Regression analysis of social anxiety and idol worship: After verifying the significance of the coefficient c, it is then necessary to verify whether the coefficient a is significant. The correlation coefficient $r$ of the social anxiety of the independent variable and the idolatry of the intermediate variable by regression analysis was 0.235 , and the Sig.p value was $0.043<0.05$, indicating that the significance was significant at the level of 0.05 , that is, the coefficient a is significant.

3) Test of the mediating effect of idol worship: Next, the coefficients $b$ and $c^{\prime}$ will be verified. After adding the mediator variable, the coefficient of idol worship is still significant at the level of 0.01 , which shows that the mediating effect of idol worship as a mediator is significant. However, the correlation coefficient $c^{\prime}$ of the independent variable is still significant at the level of 0.05 , but its correlation coefficient is reduced from the original $\mathrm{c}$ value of 0.278 to 0.225 , indicating that the mediator of idol worship plays a partial intermediary role, and the hypothesis is proved.

\section{CONCLUSION, ENLIGHTENMENTS AND EXPECTATIONS}

\section{A. Conclusion}

The theoretical assumptions are basically established, and the verification list is shown in "Table II". This paper establishes a model of social anxiety, idol worship, and worship consumption for adolescents. In the early stage, after preparations including literature theory, preparation of questionnaires, distribution and recovery questionnaires, etc., the relevant two-variable analysis and linear regression analysis techniques of spss software were used to process and integrate relevant data. For the adolescents, the social anxiety will have a positive and significant impact on their admirable consumption behavior. The more serious the social anxiety, the more inclined to pursue the worship consumption. At the same time, through the test of the mediating effect on the mediator of idol worship, it is confirmed that idol worship plays an intermediary role in the influence of social anxiety on the worship consumption.

TABLE II. SUMMARY OF HYPOTHESIS TEST RESULTS

\begin{tabular}{|l|l|l|}
\hline Hypothesis & \multicolumn{1}{|c|}{ Description } & $\begin{array}{l}\text { Assume whether } \\
\text { it is certified }\end{array}$ \\
\hline P1 & $\begin{array}{l}\text { For adolescents, social anxiety } \\
\text { has a significant positive } \\
\text { impact on idol worship }\end{array}$ & Yes \\
\hline P2 & $\begin{array}{l}\text { For adolescents, idol worship } \\
\text { has a significant positive } \\
\text { impact on admiration of } \\
\text { consumer behavior. }\end{array}$ & \\
\hline P3 & $\begin{array}{l}\text { For adolescents, idol worship } \\
\text { plays a mediating role in social } \\
\text { anxiety and admiration. }\end{array}$ & Yes \\
\hline
\end{tabular}




\section{B. Enlightenments}

First, from the perspective of individuals and families, family members should take the initiative to assume the role of important mediators in adolescents' confused adolescence. They should be good at observing the psychological and behavioral changes of adolescents, discovering problems and giving them care and help. Parents should not pay too much attention to the material love of children, but should provide them with a rich and comprehensive spiritual training to help them establish good values in life.

Second, from the perspective of social groups, it is necessary to pay more attention to the psychological demands of contemporary adolescents, build a benign competitive mechanism and smooth communication mechanism, and call on individuals, especially adolescents, to seek multi-faceted help and social development in the face of life and mental dilemmas, as well as establish a network of social trust and guide the mental health growth of adolescents from a general direction.

Third, from the perspective of the enterprise, it is crucial to seize the market opportunity to grasp the potential consumer psychology of consumers. From the conclusion of this paper, the tendency of adolescents to worship consumption will be aggravated when they face social anxiety. Enterprises should make good use of the network platform with large base, active number and good dehydration data to establish good interaction with young people. They should also pay attention to their latest preferences in real time, flexibly choose spokespersons, use celebrity effects and butterfly effects to expand their brand awareness and improve performance. Adolescents in the new generation are the main force of idol economic consumption. Only by capturing their true consumer appeals, companies in the entertainment industry and other related industries can gain a foothold in the entire market.

\section{Deficiencies and Expectations}

Although the basic theoretical assumptions of this paper have been empirically tested, the following deficiencies still exist:

First, the sample data is not representative, the number and efficiency of the questionnaire are insufficient, and the gender ratio is not fair, which may affect the analysis results. Future research should focus on the significance of sample validity, and further expansion of sample collection is needed to arrive at more accurate data and analytical conclusions.

Secondly, there are actually many factors that induce consumers to engage in worship consumption. This paper only selects one of the independent variables and one intermediate variable for analysis, and adopts four control variables such as gender, age, whether the person is only child, and monthly disposable income. It is obviously not comprehensive enough, which will affect the final analysis result to some extent. In the future, it will be necessary to build a more rigorous logical chain between variables, improve the model structure, and incorporate subjective and objective factors such as lifestyle, value orientation, peer influence, and education level into the discussion, and further integrate the analytical framework to make research more common realistic meaning.

Finally, in the process of empirical analysis, it mainly uses the correlation analysis and linear regression analysis, which makes the analysis process relatively simple. In the future research, more scientific and accurate analysis techniques can be adopted for different variables and possible relationships between variables to improve the accuracy of the analysis results.

\section{REFERENCES}

[1] Qiu Min, Social Anxiety - A Micro Level of Social Problems [J] Society, 2003 (3): 8 - 9, p1. (in Chinese)

[2] Feng Xiaotian, A Study of China's Only Child: Retrospect and Prediction $[\mathrm{J}]$ Jianghai Academic Journal, 2002 (5): 78 - 78, p4. (in Chinese)

[3] Zheng Xiaoying, Peng Siqing, Consumption as Psychological Compensation: A Review of Compensatory Consumption [J] Advances in Psychological Science, 2014, 22 (9): 1513 - 1520, p1. (in Chinese)

[4] Freud, Vorlesungen Zur Einführung in Die Psychoanalyse [M] 1917.

[5] Wu Zhongmin, Rapid Transformation of Society and Social Anxiety [J] Scientific Chinese, 2002, 37 (4): 111 - 119, p1. (in Chinese)

[6] Yue Xiaodong, Yan Fei, Exploration on the Mental Mechanism of Adolescent Idolatry $[\mathrm{J}]$ Chinese Journal of Moral Education, 2006 (12): 11 - 16, p2. (in Chinese)

[7] Pan Chaoyun, Analysis on the Worship Consumption Behaviors of Chinese Only Child Generation: An Empirical Study on the College Students Consumers [D] Guizhou University of Finance and Economics, 2011, p14. (in Chinese)

[8] Wang Guangsheng, The Influence of the New Generation Loneliness on the Worship Consumption after the 1990s [J] Consumer Economics, 2015 (6): 63 - 67. (in Chinese)

[9] Wen Zhonglin, etc., Testing and Application of the Mediating Effects [J] Acta Psychologica Sinica, 2004, 36 (5): 614 - 620. (in Chinese)

[10] Sun Xiaoling, Relationships Between Self-esteem, Rejection Sensitivity, Interpersonal Trust and Social Anxiety of Undergraduates [J] Chinese Journal of Clinical Psychology, 2011, 19 (4): 537 - 539. (in Chinese)

[11] Zhang Yanli, Analysis of Social Anxiety and Causes of Youth Groups [J] Youth Exploration, 2010 (6): 71 - 74. (in Chinese)

[12] Rui Shousheng, Talking about the Social Anxiety Problem and Coping Mechanism in the Transition Period [J] Commercial Time, 2009 (35): 8 - 9. (in Chinese)

[13] Yue Xiaodong, A Summary of the Series of Youth Idols (Part 3) Intergenerational Differences of Idols [J] Youth Studies, 2007 (5): 1 8. (in Chinese)

[14] Deng Xiaohui, Conspicuous Consumption Theory and Its Latest Development [J] Foreign Economies \& Management, 2005, 27 (4): 2 - 9. (in Chinese)

[15] Du Hezheng, Analysis on the Feasibility of Worship Consumption Status Quo and Its Student Market Potential [J] China Market, 2017 (1): 102 - 102. (in Chinese)

[16] Shen Xiangping, Modern People's Survival Anxiety [J] Journal of Shandong University of Sciences \& Technology (Social Science), 2005, 7 (3): 15 - 17. (in Chinese)

[17] Xue Xiaoyang, Youth Idol Worship - An Education Issue Worthy of Attention [J] Ideological \& Theoretical Education, 2005 (1): 33 - 36. (in Chinese)

[18] Hua Hongqin, Social Status, Life Experiences, and Anxiety [J] Society, 2013, 33 (1): 136 - 160. (in Chinese) 
[19] Lei Kaichun, Psychological Investigation and Thinking on Youth Role Model Education and Idolatry [J] Youth Studies, 2000 (5): 30 35. (in Chinese)

[20] Song Xingchuan, Multiple Choices - Youth Idol Worship Study [J] Youth Studies, 2002 (11): 1 - 7. (in Chinese)

[21] Pan Yihe, Youth "Idol Worship" Phenomenon Survey Report [J] China Youth Study, 2003 (2): 24 - 33. (in Chinese)

[22] Yu Kailiang, Seeing Youth Cultural Consumption from Idolatry [J] Youth Studies, 2001 (11): 17 - 20. (in Chinese)

[23] Feng Xiaotian, The Growing up of a New Generation: The Socialization of Chinese Only child Teen agers and Its Outcome [J] Social Sciences in China, 2000 (6): 118 - 131. (in Chinese)

[24] Qian Mingyi, A Study on the Relationship Among Adolescent's Mental Health, Self-Esteem, Self-esteem and Parental Rearing Patterns [J] Psychological Science, 1998 (6): 553 - 555. (in Chinese)

[25] Cui Lijuan, The Impact of Computer Use on Adolescents' Psychological Development [J] Psychological Science, 2003, 26 (3): 501 - 503. (in Chinese)

[26] Jin Shenghua, The Idol Worship From the Perspective of Indigenous Psychology — Take Lee Min Ho's Middle Aged Female Fans as Study Objects [J] Jilin University, 2015. (in Chinese)

[27] Schlenker, B. R., \& Leary, M. R. (1982). Social anxiety and selfpresentation: A conceptualization model.Psychological Bulletin, 92 (3), $641-669$.

[28] Charles Fairchild (2007) Building the Authentic Celebrity: The "Idol" Phenomenon in the Attention Economy, Popular Music and Society, 30: $3,355-375$.

[29] Personality and Individual Differences, The role of media figures in adolescent development: relations between autonomy, attachment, and interest in celebrities, Volume 36, Issue 4, March 2004, P813 822.

[30] Lynn E.McCutcheon Rense Lange James Houran, Conceptualization and measurement of celebrity worship, 24 December 2010. 